\title{
Perception and Willingness to Adopt a Child Among Women Attending the Infertility Clinic in a Rural Tertiary Hospital in South-South Nigeria
}

\author{
Emmanuel Friday Osagiede ${ }^{1, \text { * }}$, Oziegbe Pierre Okukpon ${ }^{1}$, Ese Tracy Abhulimhen ${ }^{2,3}$, \\ Eugene Ikhide Erah ${ }^{2}$, Valentine Abumere Enereba ${ }^{2}$, Monday Osaro Osagiede ${ }^{4}$, \\ Victor Oyelola Moody ${ }^{1}$ \\ ${ }^{1}$ Department of Community Medicine, Irrua Specialist Teaching Hospital, Irrua, Nigeria \\ ${ }^{2}$ Department of Community Health and Primary Health Care, Ambrose Alli University, Ekpoma, Nigeria \\ ${ }^{3}$ Department of Accident and Emergency, Irrua Specialist Teaching Hospital, Irrua, Nigeria \\ ${ }^{4}$ Department of Family Law, Faculty of Law, Ambrose Alli University, Ekpoma, Nigeria
}

Email address:

drosagiedeef@gmail.com (E. F. Osagiede)

${ }^{*}$ Corresponding author

\section{To cite this article:}

Emmanuel Friday Osagiede, Oziegbe Pierre Okukpon, Ese Tracy Abhulimhen, Eugene Ikhide Erah, Valentine Abumere Enereba, Monday Osaro Osagiede, Victor Oyelola Moody. Perception and Willingness to Adopt a Child Among Women Attending the Infertility Clinic in a Rural Tertiary Hospital in South-South Nigeria. Central African Journal of Public Health. Vol. 5, No. 3, 2019, pp. $102-108$. doi: 10.11648/j.cajph.20190503.11

Received: October 8, 2018; Accepted: September 11, 2018; Published: April 2, 2019

\begin{abstract}
Background: Child adoption is the legal process carried out through an open statutory or customary laws of creating a parent-child relationship between persons who are not related by blood thereby making the adopted child have equal rights, privileges, and inheritance as the biological children of the adoptive parents. Aims and Objectives: To assess the perception, attitude and willingness to adopt children among women attending infertility clinic in Irrua Specialist Teaching Hospital, Irrua, with the aim of providing information on adoption as a possible panacea to infertility management. Materials and Methods: A descriptive cross-sectional study was carried out in Irrua Specialist Teaching Hospital, Irrua, Edo State Nigeria. One hundred and thirty-four (134) women attending the infertility clinic at this facility were recruited through a systematic random sampling technique and interviewed using structured pre-tested questionnaires. The data was analysed using Statistical Package for Social Sciences (SPSS) version 20 and presented as charts, tables, and associations tested with Chi-square. Results: All of the respondents had heard of adoption, of which $91.8 \%$ knew the correct meaning of child adoption. Despite good knowledge of the meaning of adoption, only $38.1 \%$ of respondents knew what the process of adoption entails. Attitude towards child adoption was predominantly positive (73.1\%). Despite the predominantly high awareness and positive attitude for child adoption, the willingness to adopt was incongruously low. Conclusion: Willingness to adopt children among these infertile women is quite low despite good knowledge and positive attitude. Acceptability and more importantly, actual follow-through with the process of child adoption is still a core issue requiring a multi-prong approach among many childless women in developing countries.
\end{abstract}

Keywords: Perception, Willingness, Child Adoption, Women, Infertility Clinic, Nigeria

\section{Introduction}

Adoption is the process by which the legal relationship between a child and his/her natural parent is severed and is re-established with a third party. The process of child adoption is a permanent one except when a competent court of law reverses it. It is the act of legally placing a child with a parent or parents other than those to whom they were born [1]. An adoption order has the effect of severing parental responsibilities and the rights of the original parent(s) and 
transferring those responsibilities and rights to the adoptive parent(s) [1]. The adopted child has equal rights as the biological children of the adopter(s). The adoption of a child can either be an open or a fully disclosed adoption and can either be achieved by the statutory laws or the customary laws. Adoption affords those who do not have a child and those who have but desire more (and cannot have more) the opportunity to have more.

The statutory adoption law in Nigeria was given birth to in 1965 in the Eastern Region of the country. The Lagos State adoption Law closely followed that in 1968. The defunct Bendel State (now Edo and Delta States) promulgated her own adoption Law in 1979. States like Cross Rivers, Ogun, and Oyo, had theirs in 1981, 1983 and 1984 respectively. In all the existing Statutory States' laws on adoption in Nigeria, couples are allowed to adopt any sex of their choice with the consent of their spouse. However, many States in Nigeria are still without adoption law particularly in the Northern part of the country.

Infertility is the most frequent reason why couples carry out child adoption. Unfortunately, the subject, adoption is hardly discussed among most infertile couples [2]. Infertility is common in gynaecological clinic consultations in Nigeria, and the African society places a passionate premium on procreation in any family setting [3]. Other non-fertility related reasons for possible child adoption could include a desire to provide a home to a homeless child(ren) despite having theirs, to gain a child of the other gender, advanced age and the possibility of genetic problems in the person's biological child [1].

Infertility, "a disease of the reproductive system which may be defined as the failure to achieve a clinical pregnancy after a period of at least 12 months of regular unprotected sexual intercourse" is a global health issue affecting approximately $8 \%$ to $10 \%$ of couples and has been seen as the primary reason behind child adoption $[4,5]$. Worldwide, the incidence of infertility is increasing, and the prevalence varies from one region to another. For example, in some west-African communities, the infertility rate is as high as $50 \%$, while in some Western European countries it is $12 \%$ [5]. Some of the reasons for this trend could include the increasing tendency of women to delay their first pregnancy until they are in their late thirties and the much-trumpeted observation of a global reduction of male sperm count. Assisted Reproductive Technology (ART) has helped in bringing succor for couples and the procedure gradually gaining acceptance across Nigeria and other West African sub-region. However, not many couples are still able to afford the services. ART is defined as "all treatments or procedures that include the in vitro handling of both human oocytes and sperm, or embryos, to establish a pregnancy [4]."

There are not many studies carried out on child adoption in Nigeria, and the subject is even hardly discussed among the various concerned stakeholders and researchers. This article is set to examine the perception of women attending the infertility clinic in a rural tertiary hospital in South-South Nigeria and their willingness to adopt a child. In Nigeria; adoption may be effected either under statutory law or customary law. However, the rules regulating it differ from State to State. Adoption is one of the most life-transforming experiences that can happen to a child and their adoptive parents, and the government office responsible for adoption in Nigeria is the Civil Court (Juvenile, Family or Magistrate courts) [6]. Anybody that is interested in adoption in any State in Nigeria should first get him/herself familiarized with the existing adoption law (if any exist) in his or her State before going ahead with it. In States where these laws exist, there are lots of similarities in them across the different States in Nigeria [6].

For example, according to the general restrictions on the power of court to grant adoption orders in the Edo State Child Right Law 2007, it states that an adoption order shall not be made unless the following are met:- The applicant, or in the case of joint applicants, one of them is not less than twenty-five years old and is at least twenty-one years older than the child; Applicant or in the case of joint applicants both or at least one of them and the child are resident in Edo State; The child had been in the care of the applicant(s) for a period of at least three consecutive months immediately preceding the date on which the adoption order is made, and the applicant has at least three months before the making of the order to inform the probation officer of his intention to adopt the child [7]. Secondly, an adoption order shall not be made by a court in respect of a female child where the sole applicant is a male unless there are exceptional circumstances which the court thinks justifies the making of such an order [7].

Adoption under the statutory law - Those certified by a competence court as abandoned, rejected or ill-treated or whose parents cannot provide for them, as well as who were given up voluntarily by their parents are suitable for adoption. In Edo State, for instance, an application for adoption may be made by any prospective adopter(s); Any parent(s) or a person(s) with parental responsibility to look after or care for the child [7]. The Court may, upon the application of a person, in the prescribed manner, make an order (referred to as an "adoption order") authorizing such person to adopt a child or a juvenile; An adoption order may be made upon the application of spouses jointly to adopt a child but in no other case shall an adoption order be made granting leave to more than one person to adopt a child and any child above the age of one year may be voluntarily given out for adoption by his parents [7].

Although the meaning of the term juvenile and its application is not uniform across all the States in Nigeria, the statutes on adoption make provisions for juveniles to be adopted in States with adoption laws [6]. In Edo State, a Juvenile is referred to as a person under the age of eighteen (18) years who cannot be treated as an adult under the criminal justice system [7]. In Ogun, Delta, Edo, and Lagos States, before an adoption order can be made for a juvenile, such must have been abandoned, and the parents and other relatives are unknown and cannot be traced by a juvenile court [7]. It is important to state that, it seems that the 
adoption of a married person is not restricted under statutory and customary laws of most States in Nigeria except that of Oyo State. [6]. The entire adoption process and its final outcome are subsequently entered into the adoption register of the State to serves as proof of such adoption.

Adoption under the customary law - Before the advent of the colonial masters, there existed principles, notions, norms, rules, agency, and institution of law in the various geoculture groups that made up the present day Nigeria [8]. Although the English law has tremendously influenced the Nigeria legal system, the operational, legal system in Nigeria is however not only restricted to English law alone [9]. Customary law adoption in Nigeria differs from one culture to another as Nigeria is a multi-ethnic and a multi-religious country $[6,8,10-11]$.

\section{Methodology}

A descriptive cross-sectional study carried out at Irrua Specialist Teaching Hospital, Irrua, Edo State, South-South, Nigeria among consenting women who were being managed for infertility. A systematic sampling technique was used to recruit both old and new consenting patients/clients with primary infertility as well as those with secondary infertility (with or without a live-born biological child) for the study. The study was carried out between January and August 2016. Data were collected using pre-tested structured questionnaires focusing on the perceptions, attitude, and willingness to adopt a child among the selected study participants.

The questions on perception, attitude, and willingness to adopt a child were scored, aggregated, and expressed in percentages. All questions were allocated one (1) mark for all correctly answered questions, and the wrong answer allotted zero (0) score for all the variables (perception, attitude and willingness to adopt) and each session scored was weighted in percentages. The scores were grades as $75 \%-100 \%$ as good, $50 \%-74.99 \%$ as fair and $<50 \%$ as poor for knowledge and willingness to adopt a child. For attitude, a score below $60 \%$ was taken as negative while scores of $60 \%$ and above were taken as a positive attitude. Level of significant $(\alpha)$ was set at $5 \%(0.05)$ for the test of significance.

\section{Results}

A total of one hundred and forty-five (145) questionnaires was distributed, and one hundred and thirty-four (92.41\%) of them were collected in good form and analysed using Statistical Package for Social Sciences (SPSS) version 20.

Table 1. Socio-demographe characteristics of respondents.

\begin{tabular}{|c|c|c|c|}
\hline Variables & & Frequency $(n=134)$ & Percent (\%) \\
\hline \multicolumn{4}{|c|}{ Age group (years) } \\
\hline & $25-34$ & 56 & 41.8 \\
\hline & $35-44$ & 67 & 50.0 \\
\hline & $45-54$ & 11 & 8.2 \\
\hline & Mean age $\pm S D=36 \pm 5.6$ & & \\
\hline \multicolumn{4}{|c|}{ Marital status } \\
\hline & Married & 123 & 91.8 \\
\hline & Unmarried & 11 & 8.2 \\
\hline \multicolumn{4}{|c|}{ Marriage type } \\
\hline & Monogamous & 87 & 70.7 \\
\hline & Polygamous & 36 & 29.3 \\
\hline \multicolumn{4}{|l|}{ Religion } \\
\hline & Christianity & 114 & 85.1 \\
\hline & Muslim & 15 & 11.2 \\
\hline & African Tradition & 5 & 3.7 \\
\hline \multicolumn{4}{|c|}{ Level of education } \\
\hline & None & 5 & 3.7 \\
\hline & Secondary & 30 & 22.4 \\
\hline & Tertiary & 99 & 73.9 \\
\hline \multicolumn{4}{|l|}{ Occupation } \\
\hline & Farming & 5 & 3.7 \\
\hline & Civil servant & 83 & 61.9 \\
\hline & Self Employed* & 35 & 26.2 \\
\hline & Unemployed & 11 & 8.2 \\
\hline \multicolumn{4}{|c|}{ Husband's level of education } \\
\hline & Primary & 5 & 4.1 \\
\hline & Secondary & 25 & 20.3 \\
\hline & Tertiary & 93 & 75.6 \\
\hline
\end{tabular}

* Petty trading 15 (11.2\%), Shop owners 10 (7.5\%) and other businesses $10(7.5 \%)$. 
Table 2. Association between respondents'socio-demographic characteristics and perception of child adoption.

\begin{tabular}{|c|c|c|c|c|c|c|c|c|c|}
\hline \multirow{3}{*}{ Variables } & & \multicolumn{6}{|c|}{ Perception } & \multirow{3}{*}{$\chi^{2}$} & \multirow{3}{*}{ p-value } \\
\hline & & \multicolumn{2}{|c|}{ Good } & \multicolumn{2}{|c|}{ Fair } & \multicolumn{2}{|c|}{ Poor } & & \\
\hline & & $\mathbf{n}$ & $(\%)$ & $\mathbf{n}$ & $(\%)$ & $\mathbf{n}$ & $(\%)$ & & \\
\hline \multicolumn{10}{|l|}{ Age group } \\
\hline & $25-34$ & 36 & $(58.1)$ & 10 & $(17.5)$ & 10 & $(66.7)$ & 53.957 & $<0.001^{*}$ \\
\hline & $35-44$ & 20 & $(32.3)$ & 47 & $(82.5)$ & 0 & $(.0)$ & & \\
\hline & $45-54$ & 6 & $(9.7)$ & 0 & $(.0)$ & 5 & $(33.3)$ & & \\
\hline \multicolumn{10}{|c|}{ Marital status } \\
\hline & Married & 62 & $(100.0)$ & 46 & $(80.7)$ & 15 & $(100.0)$ & 16.189 & $<0.001 *$ \\
\hline & Unmarried & 0 & $(.0)$ & 11 & $(19.3)$ & 0 & $(.0)$ & & \\
\hline \multicolumn{10}{|c|}{ Marriage type } \\
\hline & Monogamous & 56 & $(90.3)$ & 26 & $(56.5)$ & 5 & $(33.3)$ & 26.115 & $<0.001 *$ \\
\hline & Polygamous & 6 & $(9.7)$ & 20 & $(43.5)$ & 10 & $(66.7)$ & & \\
\hline \multicolumn{10}{|l|}{ Religion } \\
\hline & Christianity & 57 & (91.9) & 47 & $(82.5)$ & 10 & $(66.7)$ & 44.928 & $<0.001^{*}$ \\
\hline & Muslim & 5 & $(8.1)$ & 10 & $(17.5)$ & 0 & $(.0)$ & & \\
\hline & African Tradition & 0 & $(.0)$ & 0 & $(.0)$ & 5 & $(33.3)$ & & \\
\hline \multicolumn{10}{|c|}{ Level of education } \\
\hline & None & 0 & $(.0)$ & 0 & $(.0)$ & 5 & $(33.3)$ & 56.951 & $<0.001^{*}$ \\
\hline & Secondary & 5 & $(8.1)$ & 20 & $(35.1)$ & 5 & $(33.3)$ & & \\
\hline & Tertiary & 57 & $(91.9)$ & 37 & $(64.9)$ & 5 & $(33.3)$ & & \\
\hline \multicolumn{10}{|c|}{ Duration of infertility } \\
\hline & $<5$ years & 25 & $(40.3)$ & 15 & $(26.3)$ & 5 & $(33.3)$ & 4.027 & 0.402 \\
\hline & $5-10$ years & 26 & $(41.9)$ & 27 & $(47.4)$ & 5 & $(33.3)$ & & \\
\hline & $>10$ years & 11 & $(17.7)$ & 15 & $(26.3)$ & 5 & $(33.3)$ & & \\
\hline
\end{tabular}

*Significant @ $\mathrm{p} \leq 0.05$

Table 3. Association between respondents' socio-demographic characteristics and attitude towards child adoption.

\begin{tabular}{|c|c|c|c|c|c|c|c|}
\hline \multirow{3}{*}{ Variables } & & \multicolumn{4}{|c|}{ Attitude grade } & \multirow{3}{*}{$\chi^{2}$} & \multirow{3}{*}{ P-value } \\
\hline & & \multicolumn{2}{|c|}{ Positive } & \multicolumn{2}{|c|}{ Negative } & & \\
\hline & & $\mathbf{n}$ & $(\%)$ & n & $(\%)$ & & \\
\hline \multirow{4}{*}{ Age } & group & & & & & \multirow{4}{*}{6.576} & \multirow{4}{*}{$0.037 *$} \\
\hline & $25-34$ & 36 & $(36.7)$ & 20 & $(55.6)$ & & \\
\hline & $35-44$ & 51 & $(52.0)$ & 16 & $(44.4)$ & & \\
\hline & $45-54$ & 11 & $(11.2)$ & 0 & $(.0)$ & & \\
\hline \multicolumn{8}{|c|}{ Marital status } \\
\hline & Married & 98 & $(100.0)$ & 25 & $(69.4)$ & \multirow[t]{2}{*}{32.622} & \multirow[t]{2}{*}{$<0.001 *$} \\
\hline & Unmarried & 0 & $(0.0)$ & 11 & $(30.6)$ & & \\
\hline \multicolumn{8}{|c|}{ Marriage type } \\
\hline & Monogamous & 72 & $(73.5)$ & 16 & $(44.4)$ & \multirow[t]{2}{*}{1.746} & \multirow[t]{2}{*}{0.186} \\
\hline & Polygamous & 26 & $(26.5)$ & 20 & $(55.6)$ & & \\
\hline \multicolumn{8}{|l|}{ Religion } \\
\hline & Christianity & 92 & (93.9) & 22 & $(61.1)$ & \multirow[t]{3}{*}{22.601} & \multirow[t]{3}{*}{$<0.001 *$} \\
\hline & Muslim & 5 & $(5.1)$ & 10 & $(27.8)$ & & \\
\hline & African Tradition & 1 & $(1.0)$ & 4 & $(11.1)$ & & \\
\hline \multicolumn{8}{|c|}{ Level of education } \\
\hline & No Formal Education & 0 & $(0.0)$ & 5 & $(13.9)$ & \multirow[t]{3}{*}{27.556} & \multirow[t]{3}{*}{$<0.001 *$} \\
\hline & Secondary & 15 & $(15.3)$ & 15 & $(41.7)$ & & \\
\hline & Tertiary & 83 & $(84.7)$ & 16 & $(44.4)$ & & \\
\hline \multicolumn{8}{|c|}{ Duration of infertility } \\
\hline & $<5$ years & 25 & $(25.5)$ & 20 & $(55.6)$ & \multirow[t]{3}{*}{10.739} & \multirow[t]{3}{*}{$0.005^{*}$} \\
\hline & $5-10$ years & 47 & $(48.0)$ & 11 & $(30.6)$ & & \\
\hline & $>10$ years & 26 & $(26.5)$ & 5 & (13.9) & & \\
\hline
\end{tabular}

*Significant @ $\mathrm{p} \leq 0.05$ 
Table 4. Association between respondents'socio-demographic characteristics and willingness to adopt a child.

\begin{tabular}{|c|c|c|c|c|c|c|c|c|c|}
\hline \multirow{3}{*}{ Variables } & & \multicolumn{6}{|c|}{ Willingness grade } & \multirow{3}{*}{$\chi^{2}$} & \multirow{3}{*}{ p-value } \\
\hline & & \multicolumn{2}{|c|}{ Good } & \multicolumn{2}{|l|}{ Fair } & \multicolumn{2}{|c|}{ Poor } & & \\
\hline & & $\mathbf{n}$ & (\%) & $\mathbf{n}$ & (\%) & $\mathbf{n}$ & (\%) & & \\
\hline \multicolumn{10}{|l|}{ Age group } \\
\hline & $25-34$ & 0 & $(.0)$ & 10 & $(33.3)$ & 46 & $(63.0)$ & 63.330 & $<0.001^{*}$ \\
\hline & $35-44$ & 20 & $(64.5)$ & 20 & $(66.7)$ & 27 & $(37.0)$ & & \\
\hline & $45-54$ & 11 & $(35.5)$ & 0 & $(.0)$ & 0 & $(.0)$ & & \\
\hline \multicolumn{10}{|c|}{ Marital status } \\
\hline & Married & 31 & $(100.0)$ & 30 & $(100.0)$ & 62 & $(84.9)$ & 10.014 & $0.007^{*}$ \\
\hline & Unmarried & 0 & $(.0)$ & 0 & $(.0)$ & 11 & $(15.1)$ & & \\
\hline \multicolumn{10}{|c|}{ Marriage type } \\
\hline & Monogamous & 10 & $(32.3)$ & 25 & $(83.3)$ & 52 & $(83.9)$ & 29.637 & $<0.001^{*}$ \\
\hline & Polygamous & 21 & $(67.7)$ & 5 & (16.7) & 10 & $(16.1)$ & & \\
\hline \multicolumn{10}{|l|}{ Religion } \\
\hline & Christianity & 16 & $(51.6)$ & 30 & $(100.0)$ & 68 & $(93.2)$ & 59.442 & $<0.001 *$ \\
\hline & Muslim & 15 & $(48.4)$ & 0 & $(.0)$ & 0 & $(.0)$ & & \\
\hline & African Tradition & 0 & $(.0)$ & 0 & $(.0)$ & 5 & $(6.8)$ & & \\
\hline \multicolumn{10}{|c|}{ Level of education } \\
\hline & None & 0 & $(.0)$ & 0 & $(.0)$ & 5 & $(6.8)$ & 7.412 & 0.116 \\
\hline & Secondary & 5 & $(16.1)$ & 5 & $(16.7)$ & 20 & $(27.4)$ & & \\
\hline & Tertiary & 26 & $(83.9)$ & 25 & $(83.3)$ & 48 & $(65.8)$ & & \\
\hline \multicolumn{10}{|c|}{ Duration of infertility } \\
\hline & $<5$ years & 0 & $(.0)$ & 15 & $(50.0)$ & 30 & $(41.1)$ & 85.677 & $<0.001^{*}$ \\
\hline & $5-10$ years & 5 & $(16.1)$ & 15 & $(50.0)$ & 38 & $(52.1)$ & & \\
\hline & $>10$ years & 26 & $(83.9)$ & 0 & $(.0)$ & 5 & $(6.8)$ & & \\
\hline
\end{tabular}

*Significant @ $\leq \leq 0.05$

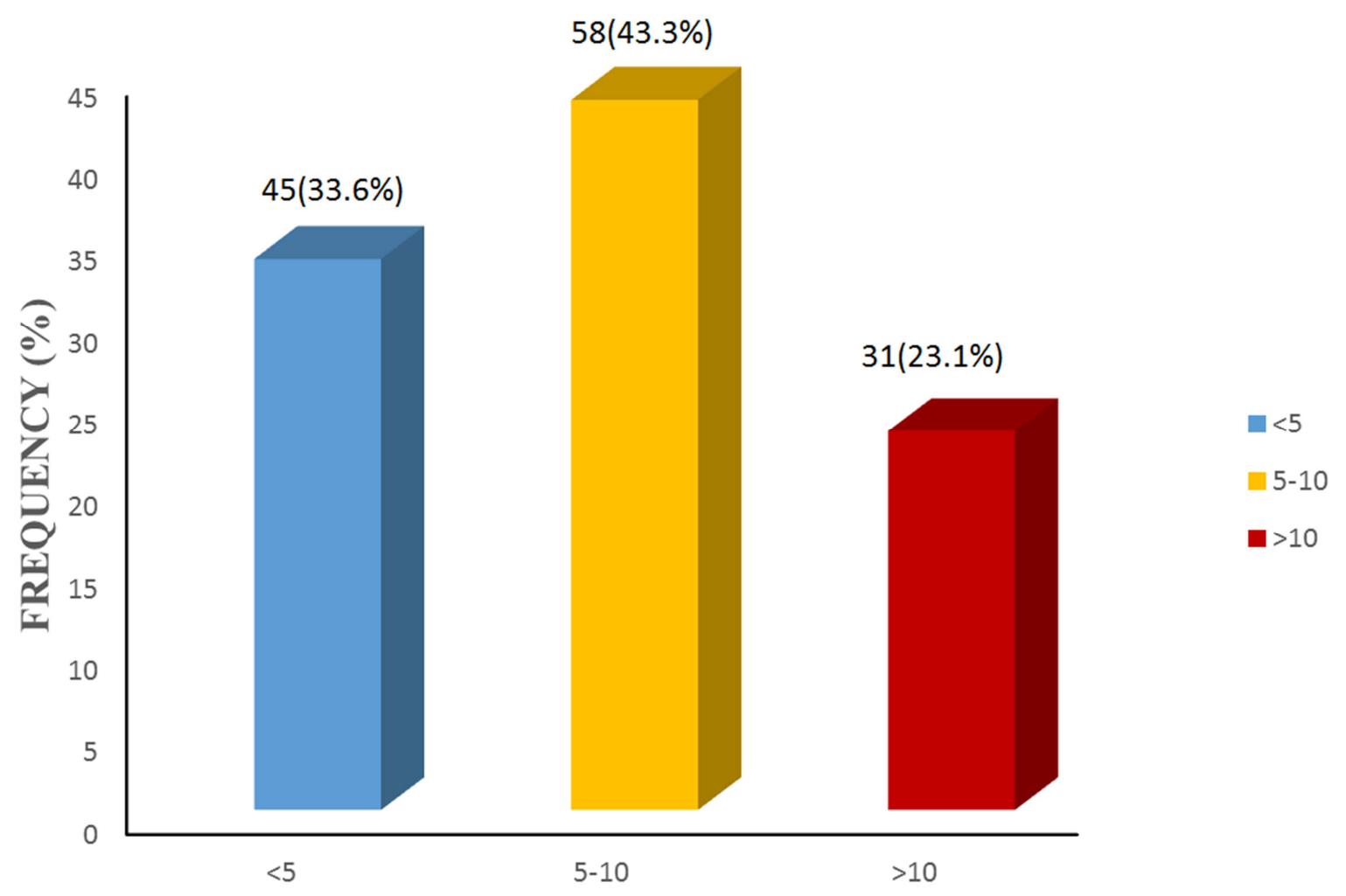

DURATION OF INFERTILITY (YEARS)

Figure 1. Duration of infertility among respondents. 


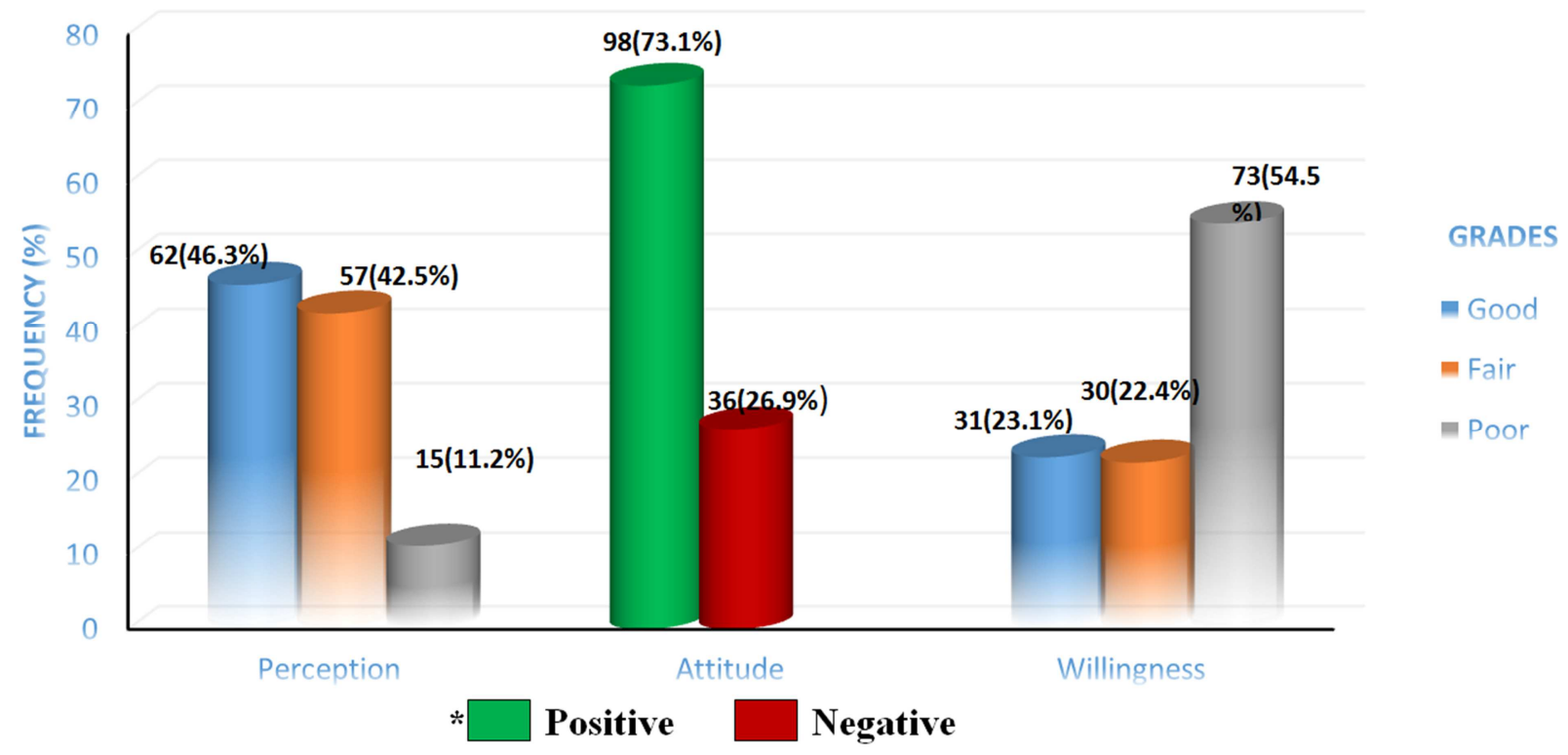

Figure 2. Respondents' perception, attitude, and willingness to adopt a child.

\section{Discussion}

Most of the respondents were within 35-44 years of age $(50 \%)$, this was similar to findings in a study conducted in Southern Nigeria at the Lagos University Teaching Hospital amongst infertile women, where the modal age group was found to be within $35-40$ years, and about half $(49.4 \%)$ of the respondents had attained a tertiary level of education [1]. This is not surprising as marriages at older ages are gradually becoming the norm as a result of the quest for more educational advancement and pursuit of career across both genders coupled with the poor economic fortunes in the developing countries like Nigeria. By the time some of these infertile women get to know of their infertility status, she has already past almost two decades of the reproductive age group.

In this study, all the respondents reported to have heard of adoption, and $91.8 \%$ of them knew the correct meaning of child adoption. This is consistent with the finding from a study carried out in Zaria, North-West Nigeria, were 89.4\% of the respondents knew the meaning of child adoption [12]. This is however in contrast with the finding in another study carried out in Lagos University teaching hospital, SouthWest, Nigeria was only a little above half of the respondents $(59.3 \%)$ knew the correct meaning of child adoption [1]. It was however revealed that despite a good knowledge of the meaning of adoption, only $38.1 \%$ of respondents knew what the process of adoption entails, though the majority (65.7\%) are aware that there are established laws governing child adoption. These findings agreed with those from other studies in Sokoto and Zaria both in NorthWest Nigeria [12, 13]. One can safely conclude that from both Northern and Southern divides of the country, though child adoption may have been unpopular in traditional African Societies, it is not a new concept to the people of Nigeria.

The longer the duration of infertility, a higher level of education, and marriage type (monogamy) were all found to be significantly correlated $(\mathrm{p}<0.05)$ with a better attitude towards child adoption. This may suggest that better knowledge of adoption, coupled with increasing pressure from friends, family members, and the society for having a child associated with a longer duration of infertility, tend to make women more favourably disposed to adoption. Although this study did not directly examine the income of respondents, there is a positive relationship between the level of education and income. In a study carried out in the United States of America, income and education were found to be the only significant predictors for adoption plans and though not for actual adoption. [14] A further analysis of this show that children who were adopted were less likely to live in impoverished households. Indicating that some households intending to adopt a child are unable to hurdle the associated barriers to adoption compare to those with more resources which might able to hurdle. [14] Contrary to the finding in this study as it relates to marriage type (monogamy) correlating with a positive attitude towards child adoption, a survey carried out in the US reported that the unmarried caregivers were more likely to consider adoption or have current plans to adopt a child [14]. There is, therefore, a need to expand the scope of future studies in developing countries to examine factors associated with actual adoption.

Generally, the respondents attitude towards adoption was predominantly positive $(73.1 \%)$ and this was relatively higher than findings in other studies earlier carried out in South-South Nigeria with below average attitude of the respondents (45.9\%) and in India (56\%) and United States of America (56\%) [15-17]. This may suggest that the concept of child adoption is gradually gaining more acceptability with improving knowledge and a better attitude towards it even in the developing nations like Nigeria. This positive attitude, when backed with action would give the opportunity to children to be adopted and these children who would have been uncared for, eventually get a place to call home. These children, when integrated into families with the right attitude 
to give them love, care, and security, will positively influence their development with the right societal values thereby given rise to a healthier society.

The willingness to adopt a child was incongruously low $(45.5 \%)$ in this study. Although comparatively, this was, however, higher than the findings in other studies in other parts of the country like Sokoto, Lagos and South-South Nigeria with percentages ranging from just about 22.7 $36.1 \%[1,13,16,17]$. On the contrary, it differs from other more recently conducted studies in Lagos and Zaria which reported $63.7 \%$ and $77 \%$ of respondents willing to adopt a child $[12,18]$. This may imply that the willingness to adopt is generally increasing but more at the urban centres than in the rural areas of Nigeria. The factors that influence the attitude toward child adoption are not different from what has been reported before; mainly, a higher level of education, and a longer duration of infertility $[18,19]$. In this study, there was a statistically significant association between longer duration of infertility and willingness to adopt a child, and this was consistent with findings from studies carried out in Sokoto and Lagos [1, 13]. Also, respondents with older age $(>35$ years) were more willing to adopt a child. This may be because they probably have stayed longer in marriage with their hope of childbearing increasingly becoming dimed whereas the intrinsic and extrinsic pressure of having a child exponentially increases.

\section{Conclusion}

There is a high level of awareness, good knowledge, and positive attitude towards child adoption that seems to be more among infertile women of older age, longer duration of infertility, higher educational status as well as in those married especially in polygamous setting. There is however an abysmally low level of willingness to adopt a child among these women which seems to be worst among those of younger age group, shorter duration of infertility and lower level of education attaned. This may indicates the relevance of advocacy, public enlightenment campaigns and health education on adoption practices as well as the need to integrate child adoption in the management of infertility to enhance adoption practices in Nigeria.

\section{References}

[1] A. O. Omosun and O. Kofoworola, "Knowledge, attitude and practice towards child adoption amongst women attending infertility clinics in Lagos State, Nigeria," African J. Prim. Heal. Care Fam. Med., vol. 3, no. 1, pp. 1-8, 2011.

[2] M. R. Welch, "Infertility: The forbidden Subject.” p. 1, 2017.

[3] O. Umeora, G. Igberase, S. Okogbenin, and I. Obu, "Misconceptions, Cultural Of, Emotional Burden In, Infertility East, South," Internet J. Gynecol. Obstet., vol. 10, no. 2, pp. $1-7,2008$.

[4] F. Zegers-Hochschild, G. D. Adamson, J. de Mouzon, O. Ishihara, R. Mansour, K. Nygren, E. Sullivan, and S.
Vanderpoel, "International Committee for Monitoring Assisted Reproductive Technology (ICMART) and the World Health Organization (WHO) revised glossary of ART terminology, 2009*," Fertil. Steril., vol. 92, no. 5, pp. 1520-1524, 2009.

[5] R. Zoe, "Causes of Infertility in Women of Reproductive Age.," Heal. Sci. J., vol. 3, no. 2, pp. 80-87, 2009.

[6] O. I. Tajudeen, "Adoption Practice in Nigeria- an Overview," J. Law, Policy Glob., vol. 19, no. Note 3, pp. 7-14, 2013.

[7] Edo State Judiciary, Edo State Family Court (Civil Procedure) Rules 2017, no. January. Nigeria, 2017, pp. 1-33.

[8] D. S. Oluya, "Bini Customary Law of Inheritance Shift in 'Igiogbe' as a Case Study," 2012.

[9] Paul Okhaide Itua, "Legitimacy, legitimation and succession in Nigeria: An appraisal of Section 42 (2) of the constitution of the Federal Republic of Nigeria 1999 as amended on the rights of inheritance," J. Law Confl. Resolut., vol. 4, no. 3, pp. 31-44, 2012.

[10] I. T. Sampson, "Religion and the Nigerian State: Situating the de facto and de jure Frontiers of State-Religion Relations and its Implications for National Security," Oxford J. Law Relig., vol. 3, no. 3, pp. 311-339, 2014.

[11] L. O. C. Chukwu, Adoption of children in Nigeria under the child's right Act 2003. pp. 1-39, 2011.

[12] S. Avidime, N. Ameh, G. A. Adesiyun, C. Ozed-Williams, N. Isaac, Y. Aliyu, K. Sullyman, H. Idris, And, and A. Ojabo, "Knowledge and attitude towards child adoption among women in Zaria, northern Nigeria.," Niger. Med. J. J. Niger. Med. Assoc., vol. 54, no. 4, pp. 261-264, 2013.

[13] E. I. Nwobodo and Y. A. Isah, "Knowledge, attitude and practice of child adoption among infertile female patients in Sokoto north-west Nigeria.,"” Niger. Postgrad. Med. J., vol. 18 , no. 4, pp. 272-275, 2011.

[14] M. D. Bramlett and L. F. Radel, "Factors Associated with Adoption and Adoption Intentions of Nonparental Caregivers," Author Manuscr., vol. 20, no. 1, pp. 5-24, 2017.

[15] B. Archana, "The factors influencing the decision for adoption among infertile couples.," Nurs. J. India, vol. xxx, no. 11, pp. 245-248, 1999.

[16] F. O. Ezugwu, S. N. Obi, and H. E. Onah, "The knowledge, attitude and practice of child adoption among infertile Nigerian women.," J. Obstet. Gynaecol. (Lahore)., vol. 22, no. 2, pp. 211-216, 2002.

[17] D. Asogun, E. Tobin, A. Esezobor, and A. Ishaq, "Child adoption amongst women attending infertility clinic in a tertiary hospital in South-South Nigeria.," Int. J. Basic, Appl. Innov. Res., vol. 4, no. 4, pp. 130-137, 2015.

[18] F. C. Ezenwankwo, A. A. Roberts, and M. R. Balogun, "Acceptability of child adoption in the management of infertility: A survey of women attending fertility clinics in the tertiary facilities in Lagos," J. Clin. Sci., vol. 11, no. 2, pp. 35$38,2014$.

[19] A. A. Adewunmi, E. A. Etti, A. O. Tayo, K. A. Rabiu, R. A. Akindele, T. A. Ottun, and et al., "Factors associated with acceptability of child adoption as a management option for infertility among women in a developing country.," Int $J$ Womens Heal., vol. 4, p. 365-72., 2012. 